\title{
Endoscopic ultrasonography with fine- needle aspiration for histological diagnosis of solid pancreatic masses: a meta-analysis of diagnostic accuracy studies
}

Omar Banafea ${ }^{1}$, Fabian Pius Mghanga ${ }^{2}$, Jinfang Zhao ${ }^{1}$, Ruifeng Zhao ${ }^{1}$ and Liangru Zhu ${ }^{1 *}$

\begin{abstract}
Background: Previous studies have demonstrated that endoscopic ultrasound-fine needle aspiration (EUS-FNA) is a reliable tool for diagnosing pancreatic lesions; however, the reported sensitivity and specificity vary greatly across studies. The aim of this study was to pool the existing literature and assess the overall performance of EUS-FNA in the diagnosis of solid pancreatic lesions.

Methods: A systematic search of MEDLINE, Cochrane Database for Systematic Reviews, and EMBASE was performed to identify original and review articles published between January 1995 and January 2014 that reported the accuracy of EUS-FNA in the diagnosis of pancreatic masses. Quality of the included studies was assessed using the quality assessment of diagnosis accuracy studies score tool. Meta-DiSc software was used to calculate the pooled sensitivity and specificity, positive and negative likelihood ratios, and to construct the summary receiver operating characteristics curve.

Results: Twenty studies involving a total of 2,761 patients were included in the study. The pooled sensitivity and specificity of EUS-FNA in the diagnosis of solid pancreatic lesions were $90.8 \%$ [95 \% confidence interval (Cl), 89.4-92 \%] and $96.5 \%(95 \% \mathrm{Cl}, 94.8-97.7 \%)$, respectively. The positive and negative likelihood ratios were $14.8(95 \% \mathrm{Cl}, 8.0-27.3)$ and 0.12 (95\% Cl, 0.09-0.16), respectively. The overall diagnostic accuracy was $91.0 \%$.

Conclusions: Our findings suggest that EUS-FNA has high sensitivity and specificity in the diagnosis of solid pancreatic lesions.

Keywords: Endoscopic ultrasound, Fine needle aspiration, Pancreatic mass

Abbreviations: AUC, Area under the curve; CT, Computed tomography; DOR, Diagnostic odd ratio; ERCP, Endoscopic retrograde chlolaniopancreatography; EUS, Endoscopic ultrasound; EUS-FNA, Endoscopic ultrasound with fine needle aspiration; FN, False negative; FP, False positive; MRI, Magnetic resonance imaging; NLRs, Negative likelihood ratio; PC, Pancreatic cancer; PLRs, Positive likelihood ratio; ROC, Receiver operating characteristic curve; ROSE, Rapid on-site evaluation; SROC, Summary receiver operating characteristic curve; TN, True negative; TP, True positive
\end{abstract}

\footnotetext{
* Correspondence: zhuliangru05@126.com

${ }^{1}$ Division of Gastroenterology, Union Hospital, Tongji Medical College,

Huazhong University of Science and Technology, No. 1277 Jiefang Avenue,

Wuhan 430022, Hubei Province, China

Full list of author information is available at the end of the article
} 
Table 1 The characteristics of included studies in current metaanalysis

\begin{tabular}{|c|c|c|c|c|}
\hline Study name & $\begin{array}{l}\text { QUADAS } \\
\text { score (14) }\end{array}$ & Study design & $\begin{array}{l}\text { Study } \\
\text { center }\end{array}$ & $\begin{array}{l}\text { On site } \\
\text { Cyto. }\end{array}$ \\
\hline Giovannini et al. 1995 [8] & 12 & $\mathrm{R}$ & S & No \\
\hline Cahn et al. 1996 [9] & 8 & $\mathrm{R}$ & M & No \\
\hline Bhutani et al. 1997 [10] & 10 & $\mathrm{p}$ & S & Yes \\
\hline Faigel et al. 1997 [11] & 12 & $P$ & S & Yes \\
\hline Chang et al. 1997 [23] & 11 & $P$ & S & No \\
\hline Bentz et al. 1998 [24] & 13 & $P$ & S & Yes \\
\hline Voss et al. 2000 [12] & 12 & $P$ & S & No \\
\hline Gress et al. 2001 [13] & 11 & $\mathrm{p}$ & S & No \\
\hline Ylagan et al. 2002 [14] & 10 & $\mathrm{R}$ & S & No \\
\hline Harewood 2002 [15] & 13 & $P$ & M & Yes \\
\hline Raut et al. 2003 [16] & 13 & $P$ & S & No \\
\hline Afify et al. 2003 [17] & 11 & $\mathrm{R}$ & S & Yes \\
\hline Agarwal et al. 2004 [18] & 11 & $\mathrm{R}$ & S & No \\
\hline Ryozawa et al. 2005 [19] & 9 & $\mathrm{R}$ & M & Yes \\
\hline Eloubeidi et al. 2007 [20] & 13 & $P$ & S & No \\
\hline Fisher et al. 2009 [25] & 13 & $P$ & S & No \\
\hline Krishna et al. 2009 [21] & 12 & $P$ & S & Yes \\
\hline Touchefeu et al. 2009 [22] & 13 & $P$ & S & No \\
\hline Cherian et al. 2010 [7] & 10 & $P$ & S & No \\
\hline Uehara et al. 2011 [26] & 9 & $\mathrm{R}$ & $S$ & No \\
\hline
\end{tabular}

$P$ Prospective, $R$ Retrospective, $M$ Multiple centers, $S$ Single center

\section{Background}

Pancreatic cancer is the tenth most common type of cancer, and the fourth leading cause of cancer-related deaths among men and women, accounting for $6 \%$ of all cancer-related deaths worldwide [1]. Pancreatic cancer is difficult to diagnose in its early stages, and nearly $26 \%$ of all diagnosed cases have regional spread, with $52 \%$ of cases reported to have metastatic disease at the time of diagnosis [2]. Studies have shown that one-year survival rate for pancreatic cancer is $24 \%$, and the overall 5-year survival rate is $5 \%$ [2]. Since curative resection is currently the only potential cure for patients with pancreatic cancer, early diagnosis has an important impact on prognosis.

Pancreatic lesions encompass a variety of benign and malignant conditions, and the diagnosis of pancreatic cancer is complicated by indistinct detection of pancreatic masses either clinically or by imaging. Clinically, the diagnosis of a regional pancreatic mass may be confused with that of a primary pancreatic tumor, as in pancreatic adenocarcinoma, while focal chronic pancreatitis may be confused with pancreatic metastasis from a distant primary tumor [3]. Thus, accurate preoperative diagnosis is essential for selecting an appropriate treatment for these lesions [4].
Currently, there are many laboratory tests and imaging techniques that may be useful in discriminating pancreatic lesions [5, 6]. Among them, cytological examination of pancreatic masses by fine needle aspiration (FNA) can assist greatly in differentiating a pancreatic tumor from other malignancies. Endoscopic ultrasound (EUS), due to its high resolution, can provide easy visualization of the pancreas, common bile duct and adjacent anatomic structures, and has been the most important imaging modality for the diagnosis of pancreatic tumors [7]. EUS combined with FNA (EUS-FNA) has been demonstrated to be more accurate in diagnosing solid pancreatic lesions and has gained wide acceptance [7]. However, the reported sensitivity and specificity of EUS-FNA vary greatly across studies (sensitivity: $73.20-96.50 \%$; specificity: $71.40-100 \%$ ) [7-26]. In addition, the majority of previous studies were dependent on single-center trials. Since there is a learning curve for FNA, its diagnostic accuracy is greatly influenced by operator experience [22]. In addition, the performance of FNA may be related to the size and location of pancreatic lesions and the presence of an on-site cytopathologist [7, 26]. At present, there has been no systematic approach to estimate the accuracy of EUS-FNA in diagnosing solid pancreatic lesions.

The current meta-analysis aimed at reviewing the existing literature and evaluating the overall performance of EUS-FNA in diagnosing solid pancreatic lesions.

\section{Methods}

\section{Identification of studies}

A systematic search of PubMed (including MEDLINE compiled by the United States National Library of Medicine, Bethesda, Maryland, USA), EMBASE (Elsevier, Amsterdam, Netherlands), and the Cochrane Database for Systematic Reviews (The Cochrane Collaboration, Oxford, UK) was performed to identify published original and review articles reporting the accuracy of EUS-FNA in the diagnosis of pancreatic masses. The electronic search was supplemented by a manual search of the listed references. Searches were limited to studies conducted from January 1995 to January 2014. We used the keywords ["pancreatic mass" or "pancreatic lesion" or "pancreatic tumor"] and ["endoscopic ultrasound" or "endoscopic ultrasound fine needle aspiration" or "EUS-FNA" or "EUS-FNA in pancreatic lesions")] and ["sensitivity" or "specificity" or "diagnostic accuracy"].

We identified 285 studies through this search strategy. We also hand-searched several imaging and oncology journals for the specified period to ensure that the electronic search did not miss reports of eligible studies; no additional study was identified using this strategy. 


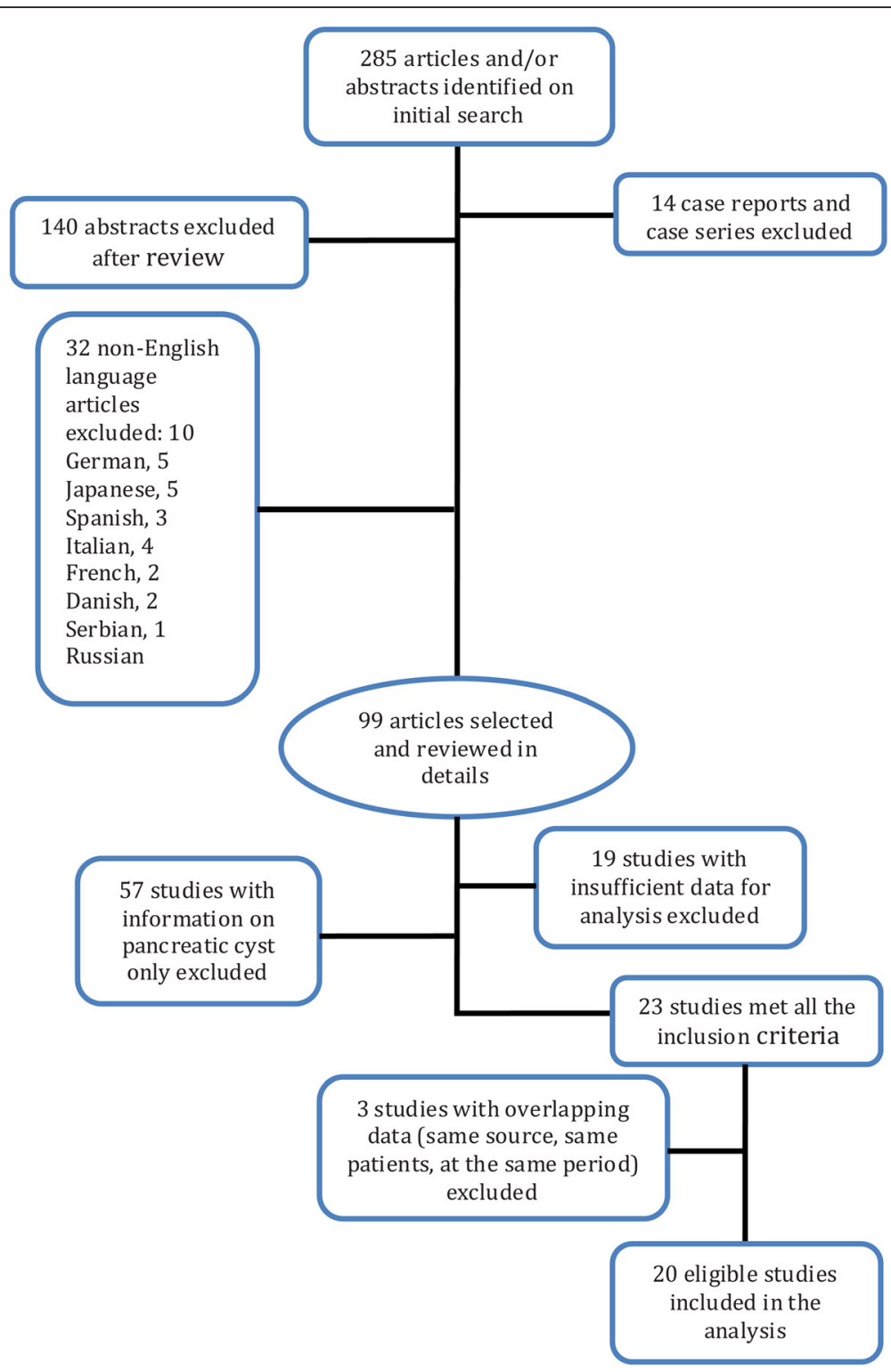

Fig. 1 Flow diagram of the study selection process

The reference list of the retrieved studies was searched for any additional publications, and none of the articles was found in this approach. We restricted searching to studies that were published in English only and included more than 10 patients.

\section{Eligibility criteria}

Studies were eligible for inclusion if they fulfilled the following criteria: (i) articles were published in English; (ii) appropriate data were presented to enable computation of true positive (TP), false negative (FN), false positive (FP) and true negative (TN) results of EUS-FNA in the diagnosis of solid pancreatic lesions; (iii) at least 10 patients and/or lesions were included; (iv) a final diagnosis was obtained by surgical biopsy or histological examination of surgically resected specimen; (v) the population had a suspected solid pancreatic mass based on imaging modalities such as ultrasound, EUS, computed tomography (CT) and magnetic resonance imaging (MRI), and only patients who had a solid pancreatic mass (in case of mixed lesions, separate results were reported for solid and cystic lesions) were included in the study; (vi) studies were retrospective and/or prospective, and had results of EUS-FNA based on surgical cytological/ histological specimens, or a follow-up period of at least 6 months; and (vii) articles were published from January1995 to January 2014. 
Table 2 Complications of EUS-FNA reported in the included studies

\begin{tabular}{|c|c|c|c|}
\hline Study & Number & Percent & Post-procedural complications \\
\hline Giovannini et al. 1995 [8] & 0 & 0 & No complications reported \\
\hline Cahn et al. 1996 [9] & Unknown & - & - \\
\hline Bhutani et al. 1997 [10] & $1 / 47$ & 2 & Infection $(n=1)$ \\
\hline Faigel et al. 1997 [11] & $0 / 45$ & 0 & No complications reported \\
\hline Chang et al. 1997 [23] & $1 / 44$ & 2 & Fever $(n=1)$ \\
\hline Bentz et al. 1998 [24] & Unknown & - & - \\
\hline Voss et al. 2000 [12] & $5 / 90$ & 5 & Bleeding $(n=4)$, abdominal pain $(n=1)$ \\
\hline Gress et al. 2001 [13] & $3 / 102$ & 2.9 & Gastric mucosal bleeding $(n=2)$, pancreatitis $(n=1)$ \\
\hline Ylagan et al. 2002 [14] & $1 / 91$ & 1 & Acute pancreatitis $(n=1)$. \\
\hline Harewood 2002 [15] & $1 / 185$ & 0.5 & Mild pancreatitis $(n=1)$. \\
\hline Raut et al. 2003 [16] & $4 / 233$ & 2 & Duodenal perforation $(n=2)$, abdominal pain $(n=1)$, pancreatitis $(n=1)$ \\
\hline Afify et al. 2003 [17] & Unknown & - & - \\
\hline Agarwal et al. 2004 [18] & $2 / 81$ & 2.5 & Abdominal pain $(n=2)$ \\
\hline Ryozawa et al. 2005 [19] & 0 & 0 & No complications reported \\
\hline Eloubeidi et al. 2007 [20] & $11 / 547$ & 2 & Acute pancreatitis $(n=5)$, abdominal pain $(n=3)$, fever $(n=2)$, the use of reversal medication $(n=1)$ \\
\hline Fisher et al. 2009 [25] & $2 / 100$ & 2 & Mucosal bleeding $(n=1)$, abdominal pain $(n=1)$ \\
\hline Krishna et al. 2009 [21] & Unknown & - & - \\
\hline Touchefeu et al. 2009 [22] & 2/90 & 2.2 & Fever $(n=1)$, abdominal pain $(n=1)$ \\
\hline Cherian et al. 2010 [7] & Unknown & - & - \\
\hline Uehara et al. 2011 [26] & $2 / 120$ & 1.6 & Mild pancreatitis $(n=2)$ \\
\hline
\end{tabular}

We excluded: (i) case reports and abstracts; (ii) studies that did not report sufficient data to construct a diagnostic $2 \times 2$ contingency table to calculate statistics including TP, FP, TN and FN; and (iii) studies involving patients with a cystic lesion or other malignancy like cholangiocarcinoma, duodenal adenocarcinoma, and periampullary adenocarcinoma and studies that involved other FNA procedures like CT-guided FNA or MRIguided FNA. We excluded cystic lesions from the current analysis, because their diagnosis and management were different from those of solid pancreatic lesions [27].

\section{Study quality assessment}

We used the quality assessment of diagnosis accuracy studies (QUADAS) tool [28] to assess the methodological quality of the included studies. The tool had 14 questions with responses denoted as "yes," "no," or "unavailable." A score of 1 was given to a "yes" response, and a score of zero was given if the response was "no" or "unavailable". An article was deemed of adequate quality for inclusion if it scored a minimum of 8 of 14 points in the "QUADAS" checklist as in Table 1.

\section{Data extraction}

Data from all eligible studies were extracted independently by two of the authors (O.B and F.P.M).
Information extracted included the first author's name, journal, year of publication, study design, sample size and clinical indication. We also extracted demographic characteristics including mean or median age, patient gender, number of lesions and lesion size. Other extracted information included needle manufacturing company, frequency of EUS, needle size and number of needles that passed through the lesion during procedure. In cases of any differences between the two authors, a consensus was reached by discussion.

\section{Statistical analysis}

For each included study, we constructed a $2 \times 2$ table to calculate the TP, FN, FP and TN values. The data were then analyzed using Meta-DiSc software (version 1.4; Unit of Clinical Biostatistics Team of the Romany Cajal Hospital, Madrid, Spain) to compute sensitivity, specificity, positive likelihood ratio, negative likelihood ratio, positive predictive value (PPV), negative predictive value (NPV) and diagnostic odds ratio (DOR) for each study. As per the DerSimonian-Liard random effects model, we pooled all results and using the same model, we constructed a summary receiver operating characteristic curve (SROC). By numeric integration of the SROC using the trapezoidal equation, the software was used to compute the area under the curve (AUC). A preferred test has an AUC close to 1, and 


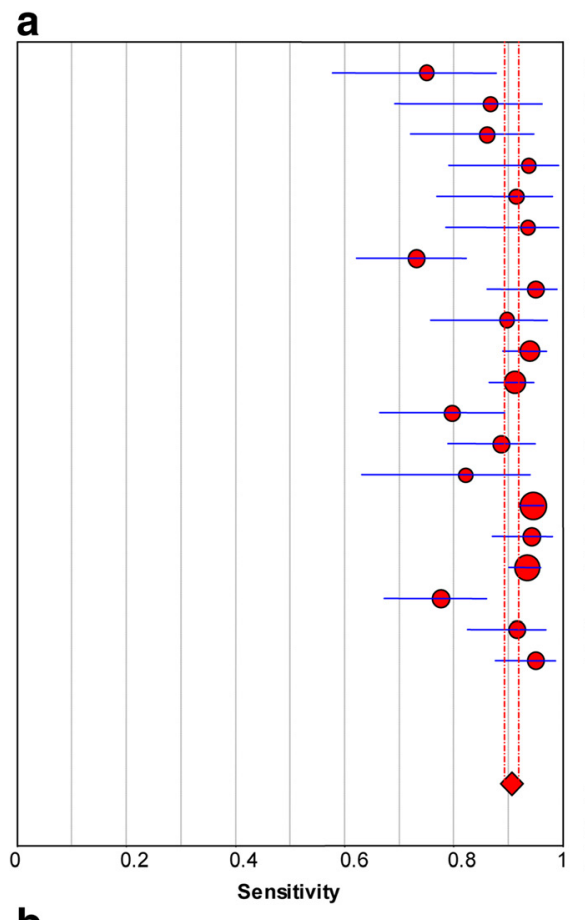

b

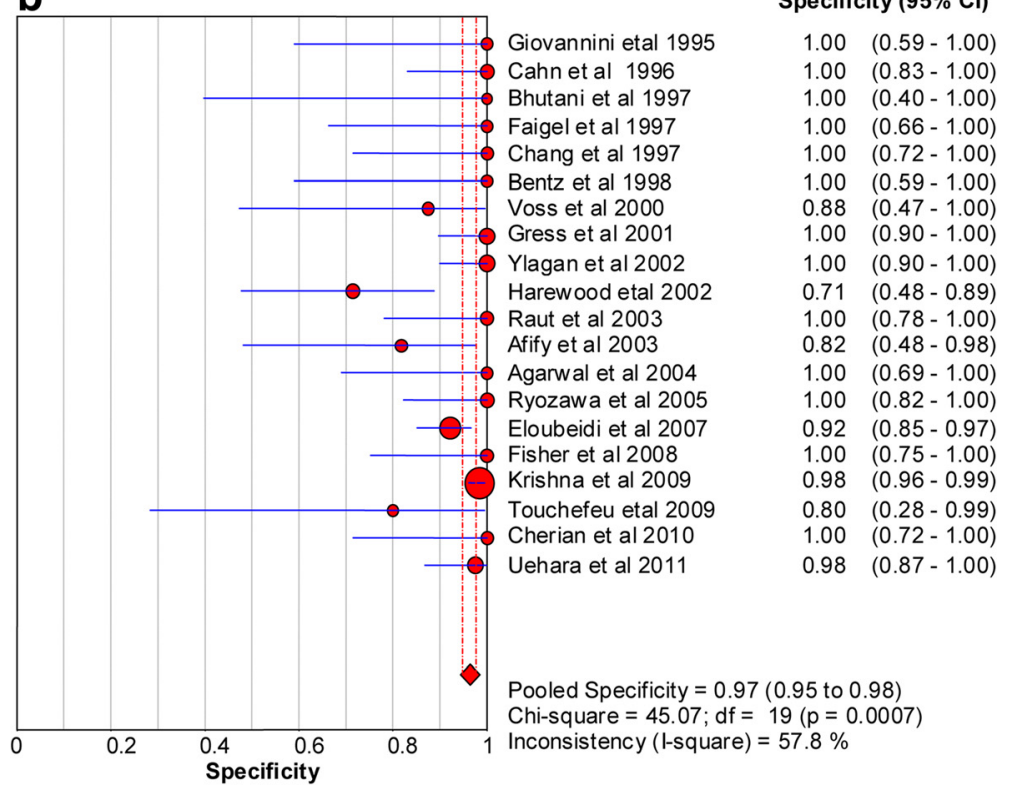

Sensitivity $(95 \% \mathrm{Cl})$

Giovannini etal $1995 \quad 0.75 \quad(0.58-0.88)$

Cahn et al $1996 \quad 0.87 \quad(0.69-0.96)$

Bhutani et al $1997 \quad 0.86 \quad(0.72-0.95)$

Faigel et al $1997 \quad 0.94 \quad(0.79-0.99)$

Chang et al $1997 \quad 0.91 \quad(0.77-0.98)$

Bentz et al $1998 \quad 0.94 \quad(0.79-0.99)$

Voss et al $2000 \quad 0.73 \quad(0.62-0.82)$

Gress et al $2001 \quad 0.95 \quad(0.86-0.99)$

Ylagan et al $2002 \quad 0.90 \quad(0.76-0.97)$

Harewood etal $2002 \quad 0.94 \quad(0.89-0.97)$

Raut et al $2003 \quad 0.91 \quad(0.87-0.95)$

Afify et al $2003 \quad 0.80 \quad(0.66-0.89)$

Agarwal et al $2004 \quad 0.89 \quad(0.79-0.95)$

Ryozawa et al $2005 \quad 0.82 \quad(0.63-0.94)$

Eloubeidi et al $2007 \quad 0.95 \quad(0.92-0.96)$

Fisher et al $2008 \quad 0.94 \quad(0.87-0.98)$

Krishna et al $2009 \quad 0.93 \quad(0.90-0.96)$

Touchefeu etal $2009 \quad 0.78 \quad(0.67-0.86)$

Cherian et al $2010 \quad 0.92 \quad(0.83-0.97)$

Uehara et al $2011 \quad 0.95 \quad(0.88-0.99)$

Pooled Sensitivity $=0.91(0.89$ to 0.92$)$

Chi-square $=71.20 ; d f=19(p=0.0000)$

Inconsistency (l-square) $=73.3 \%$

Fig. 2 Forest plots of sensitivity (a) and specificity (b)

an AUC close to 0.5 is considered a poor test. NPV and FP rate (i.e., 1 - specificity) were also calculated. $Q^{*}$, the maximum joint specificity and sensitivity, was calculated from the SROC. This is the point on the SROC curve where sensitivity is equal to specificity. A chi-square test was used to test for the occurrence of heterogeneity among studies, and sources of heterogeneity were explored using meta-regression analysis. $P$-values $<0.05$ were considered statistically significant.

\section{Results}

\section{Eligible studies}

Our searches yielded a total of 285 titles and abstracts. Of these, 140 abstracts and 32 studies published in languages other than English (10 in German, 5 in Japanese, 5 in Spanish, 4 in French, 3 in Italian, 2 in Danish, 2 in Serbian and 1 in Russian) were excluded. Upon further review of the studies, 14 case reports and case series with a sample size less than 10 patients were excluded. We also excluded 57 studies with information on 


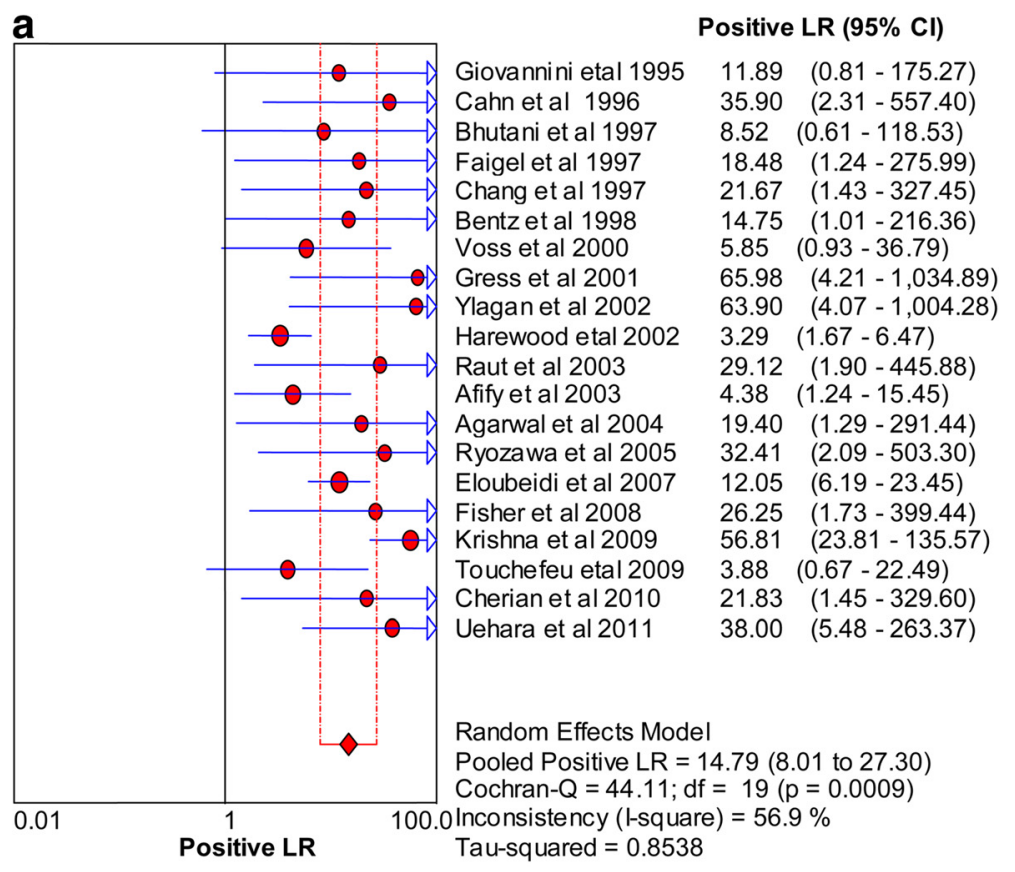

b

Negative LR $(95 \% \mathrm{Cl})$

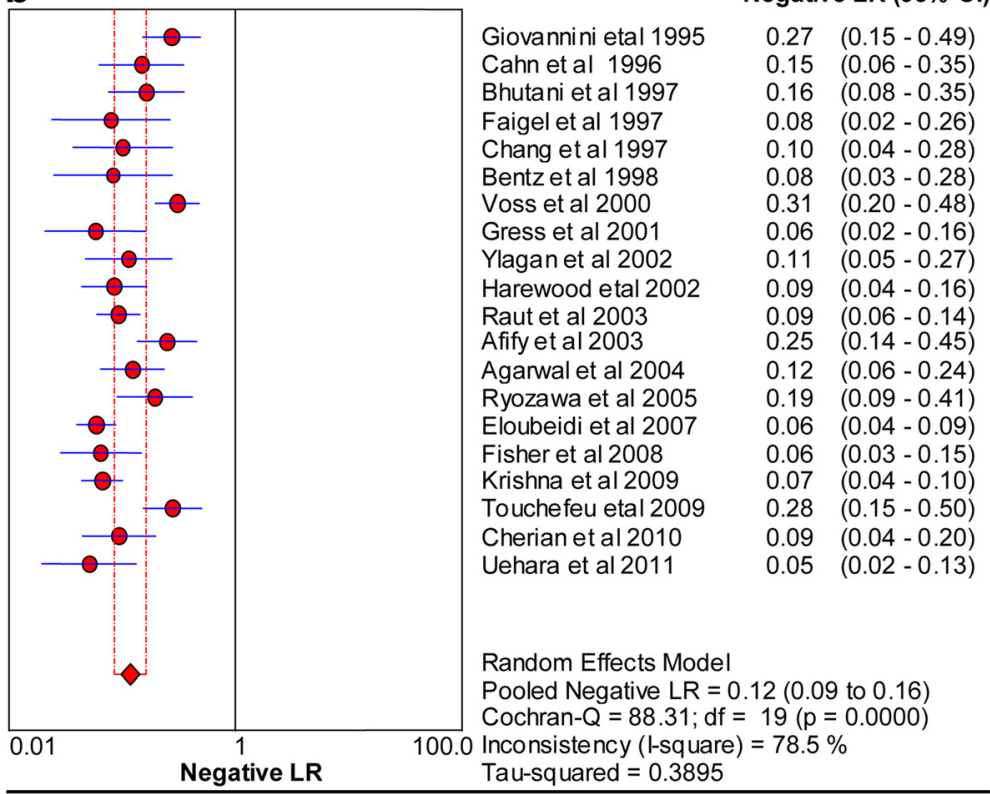

Fig. 3 Forest plots of positive likelihood ratio (a) and negative likelihood ratio (b)

pancreatic cyst only and 19 studies with insufficient data. Five duplicate studies, three in one batch and two in the other, had the same sources of data, so we excluded the 3 studies from the duplicated studies and included the 2 studies that had included data from the same database (Table 3). Finally, a total of 20 studies [7-26] were eligible for analysis based on the inclusion and exclusion criteria. Figure 1 shows the flow chart of study selection.

\section{Study description and patient characteristics}

Of the 20 studies included, 13 were prospective [7, 10-13, $15,16,19,20-25]$ and 7 were retrospective $[8,9,14,17-$ 19, 26] (Table 1). The studies involved a total of 2,761 patients with a total of 2,776 pancreatic lesions. The median age of the subjects was reported in 15 articles, and 5 did not mention the age of the patients. The male/female ratio of the study subjects was 1.3:1. 


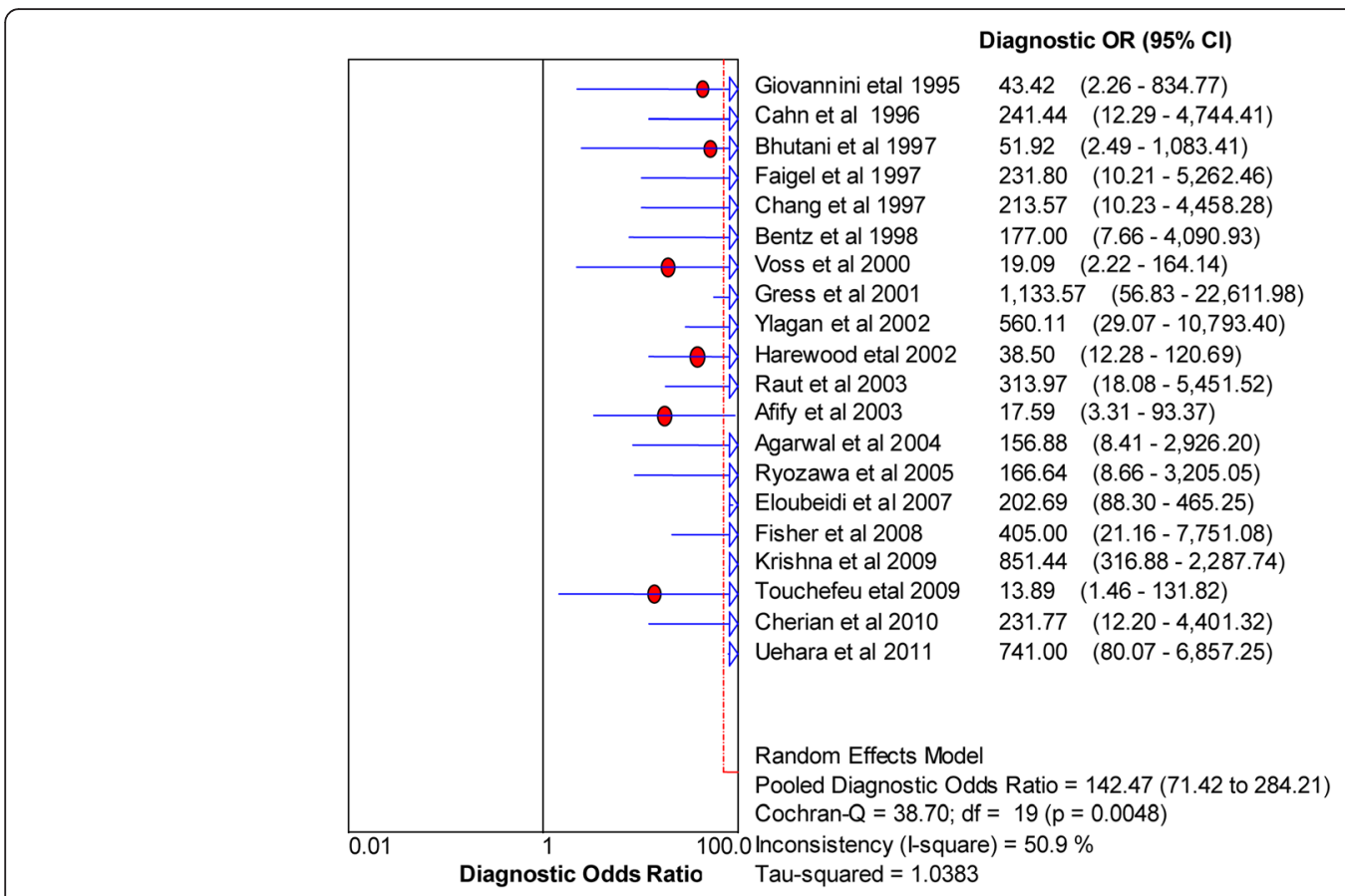

Fig. 4 Forest plot of diagnostic odds ratio

\section{EUS-FNA techniques}

The majority of studies used 22-gauge needles in EUSFNA procedures [7, 11, 13-22, 24-26], although some of these needles were made by different manufacturers. Other sizes used were 19-gauge (Wilson cook, Winston
Salem, North Carolina NC) $[10,13]$ and 25-gauge (manufacturing company not mentioned) needles [8].

Fifteen of the 20 included studies mentioned pancreatic mass size which varied between 0.6 and $14 \mathrm{~cm}$ whereas the rest 5 studies did not mention the size of

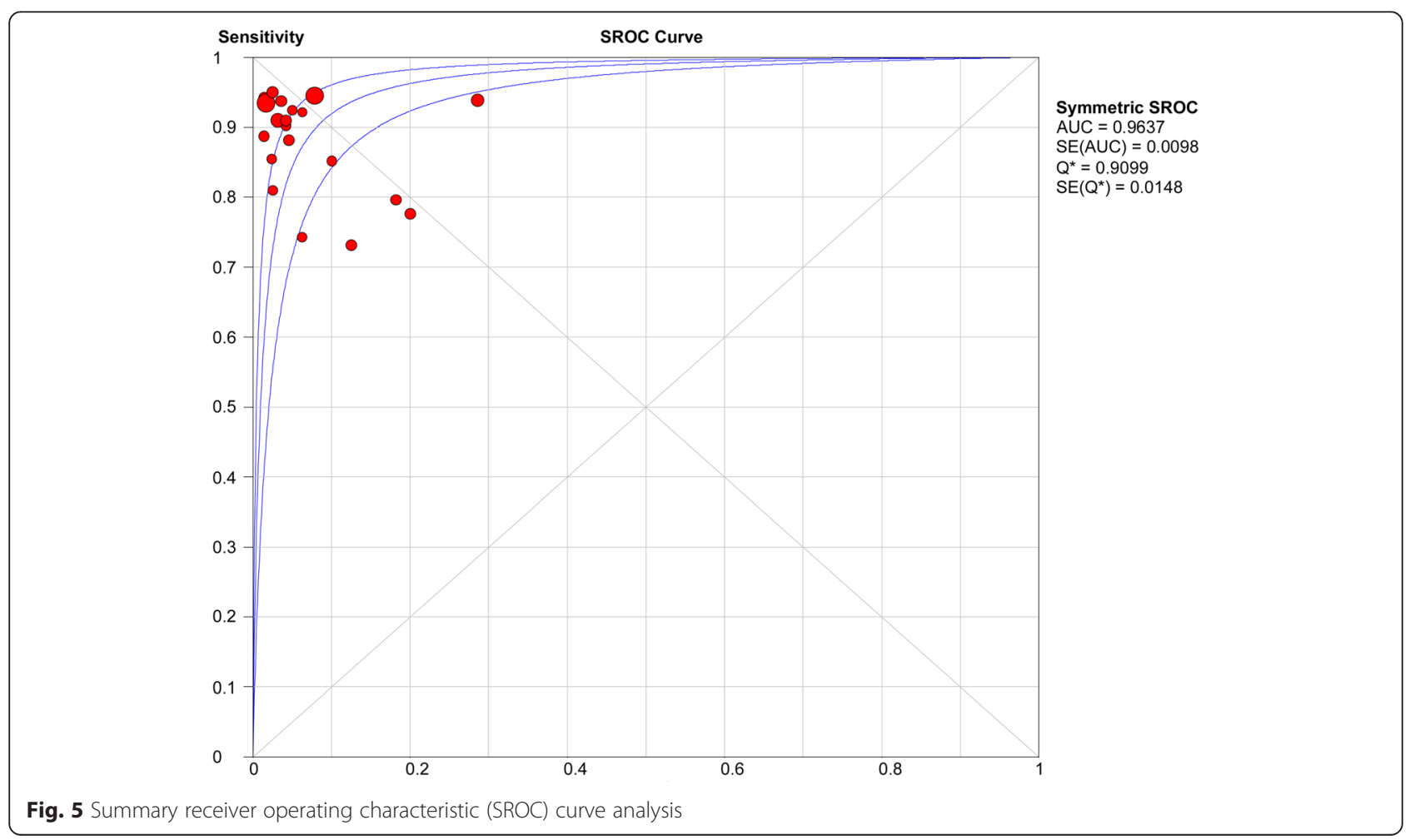


Table 3 Summary of diagnostic performance of endoscopic ultrasonography with fine-needle aspiration for solid pancreatic lesions

\begin{tabular}{|c|c|c|c|c|c|c|c|c|c|c|}
\hline Study & Year & TP & $\mathrm{FP}$ & FN & $\mathrm{TN}$ & Sensitivity & Specificity & LR+ & LR- & DOR \\
\hline Giovannini & 1995 & 27 & 0 & 9 & 7 & $75(58-88)$ & $100(59-100)$ & $11.9(0.81-175)$ & $0.3(0.15-0.49)$ & $43(2-835)$ \\
\hline Cahn & 1996 & 26 & 0 & 4 & 20 & 87 (69-96) & $100(83-100)$ & $35.9(2.3-557)$ & $0.15(0.06-0.4)$ & $241(12-4744)$ \\
\hline Bhutani & 1997 & 37 & 0 & 6 & 4 & $86(72-94)$ & $100(40-100)$ & $8.5(0.6-118.5)$ & $0.16(0.08-0.35)$ & $52(2.5-1083)$ \\
\hline Faigel & 1997 & 30 & 0 & 2 & 9 & 94 (79-99) & $100(66-100)$ & $18.5(1.2-276)$ & $0.08(0.02-0.27)$ & $232(10-5263)$ \\
\hline Chang & 1997 & 32 & 0 & 3 & 11 & 91 (77-98) & $100(72-100)$ & $21.7(1.4-327.5)$ & $0.1(0.04-0.28)$ & 214(10-4458) \\
\hline Bentz & 1998 & 29 & 0 & 2 & 7 & 94 (79-99) & $100(59-100)$ & $14.8(1-216.4)$ & $0.08(0.025-0.28)$ & 177(8-4090) \\
\hline Voss & 2000 & 60 & 1 & 22 & 7 & $73(62-82)$ & 88 (47-99.7) & $5.8(0.9-36.8)$ & $0.3(0.2-0.48)$ & $19(2.2-164)$ \\
\hline Gress & 2001 & 57 & 0 & 3 & 34 & 95 (86-99) & $100(90-100)$ & $66(4.2-1035)$ & $0.06(0.02-0.16)$ & 1134 (56.828-22612) \\
\hline Ylagan & 2002 & 35 & 0 & 4 & 35 & $90(76-97)$ & $100(90-100)$ & $63.9(4.1-1004)$ & $0.11(0.048-0.27)$ & 560(29-10793) \\
\hline Harewood & 2002 & 154 & 6 & 10 & 15 & 94 (89-97) & $71(48-89)$ & $3.3(1.7-6.5)$ & $0.09(0.044-0.17)$ & $39(12-121)$ \\
\hline Raut & 2003 & 197 & 0 & 19 & 15 & $91(87-95)$ & $100(78-100)$ & $29(1.9-446)$ & $0.09(0.06-0.14)$ & $314(18.083-5451.5)$ \\
\hline Afify & 2003 & 43 & 2 & 11 & 9 & $80(67-89)$ & $82(48-98)$ & $4.4(1.2-15.5)$ & $0.25(0.14-0.45)$ & $18(3-93)$ \\
\hline Agarwal & 2004 & 63 & 0 & 8 & 10 & 89 (79-95) & $100(69-100)$ & $19(1.3-291)$ & $0.12(0.07-0.24)$ & $157(8-2926.2)$ \\
\hline Ryozawa & 2005 & 23 & 0 & 5 & 19 & $82(63-94)$ & $100(82-100)$ & $32.4(2.1-503)$ & $0.2(0.09-0.414)$ & $166(9-3205)$ \\
\hline Eloubeidi & 2007 & 414 & 8 & 24 & 94 & 95 (92-97) & $92(85-97)$ & $12.1(6.2-23.5)$ & $0.06(0.04-0.09)$ & $202.6988 .302-465.25$ \\
\hline Fisher & 2009 & 82 & 0 & 3 & 13 & 97 (90-99) & $100(75-100)$ & $26.3(1.7-399)$ & $0.07(0.03-0.15)$ & $405(21.2-7751)$ \\
\hline Krishna & 2009 & 299 & 5 & 21 & 299 & $93(90-96)$ & 98 (96-99.5) & 57 (24-136) & $0.07(0.044-0.1)$ & 851 (317-2288 \\
\hline Touchefeu & 2009 & 66 & 1 & 19 & 4 & $78(67-86)$ & 80 (28-99.5) & $3.9(0.7-22.5)$ & $0.28(0.16-0.5]$ & $13.9(1.5-132)$ \\
\hline Cherian & 2010 & 65 & 0 & 6 & 11 & $92(83-97)$ & $100(72-100)$ & $22(2-330)$ & $0.09(0.05-0.2)$ & $232(12-4401)$ \\
\hline Uehara & 2011 & 76 & 1 & 4 & 39 & 95 (88-99) & $98(87-100)$ & $38(6-263)$ & $0.05(0.02-0.13]$ & 741 (80-6857) \\
\hline
\end{tabular}

$T P$ true positive, $F P$ false positive, $F N$ false negative, $T N$ true negative, $L R+$ positive likely ratio, $L R$ - negative likely ratio, $D O R$ Diagnostic Odds Ratio

masses [7, 9-13, 15, 18-20, 22-26]. The mean tumor size was $3.4 \mathrm{~cm}$, with a range of $0.6-14 \mathrm{~cm}$. The median number of needle passes through each pancreatic lesion was 3.4, ranging between 1 and 5 .

\section{Safety of EUS-FNA}

As shown in Table 2, actual complications of EUS-FNA procedures occurred in 35 of 1,760 patients in 15 studies that mentioned complications $[7,8,10-13,15,16,19$, $20,22,23,25,26]$, mainly abdominal pain, pancreatitis, hematoma, bleeding at needle sites and fever (not accompanied by other symptoms). There were two cases of major complication (duodenal perforations, which were immediately managed by laparotomy).

\section{Pooled results}

The sensitivity and specificity of EUS-FNA in the diagnosis of solid pancreatic masses were found to range from 73.20 to $96.50 \%$ and 71.40 to $100 \%$, respectively. The median sensitivity and specificity were $91.30 \%$ and $100 \%$, respectively. The pooled sensitivity and specificity were $90.80 \%$ [95 \% confidence interval (CI): 89.40$92.00 \%$ ] and $96.5 \%$ (95\%CI: 94.8-7.7\%), respectively (Fig. 2). The positive and negative likelihood ratios were 14.80 (95\%CI, 8.00-27.30) and 0.12 (95\%CI, 0.09-0.16), respectively (Fig. 3). The diagnostic odds ratio is 142.47 (71.42-284.21) (Fig. 4).

\section{ROC analysis}

The AUC was used to summarize the overall diagnostic accuracy of EUS-FNA. From the curve, the maximum joint sensitivity and specificity, denoted as $Q^{*}$ (the point at which the sensitivity and specificity of a diagnostic tool are equal), was found to be $91.0 \%$ (Fig. 5). This finding suggests a relatively high overall diagnostic performance of EUS-FNA in the diagnosis of solid pancreatic lesions.

\section{Sources of heterogeneity}

To explore potential sources of heterogeneity, a metaregression analysis was performed. A multivariable regression model with a backward stepwise algorithm was used. The possible sources of heterogeneity in our study included publication bias, study design and methodological quality. None of the analyzed variables showed statistical significance (Table 3), e.g., higher quality studies (QUADAS score $\geq 10$ ) and lower quality studies (QUADAS score $<10$ ) were not significantly different.

\section{Discussion}

Many previous studies have demonstrated that EUSFNA is a reliable tool for the diagnosis of pancreatic masses; however, the reported sensitivity and specificity varied greatly among these different studies [7-26]. In this study, we conducted a meta-analysis to pool the 
Table 4 Diagnostic accuracy of all 20 included studies

\begin{tabular}{|c|c|c|c|c|c|c|}
\hline & No. of studies & Sensitivity & Specificity & $\mathrm{LR}(+)$ & LR(-) & DOR \\
\hline \multirow[t]{2}{*}{ All of 20 studies } & & 90.80 & 96.5 & 14.80 & 0.12 & 142.47 \\
\hline & 20 & & & & & \\
\hline$P$ & & 0 & .0007 & 0.0009 & 0.000 & 0.0048 \\
\hline \multicolumn{7}{|l|}{ Study design: } \\
\hline Prospective & 13 & 91.4 & 94.3 & 10.928 & 0.110 & 122.14 \\
\hline \multicolumn{7}{|l|}{$P$} \\
\hline & & 0 & 0.006 & 0.130 & 0 & 0.348 \\
\hline \multicolumn{7}{|l|}{ Study design: } \\
\hline Retrospective & 7 & 89.5 & 97.9 & 19.004 & 0.128 & 162.38 \\
\hline$P$ & & 0.001 & 0.076 & 0.009 & 0 & 0.001 \\
\hline QUADAS score $\geq 10$ & & 90.8 & 96.2 & 13.162 & 0.116 & 127.44 \\
\hline \multirow[t]{2}{*}{$P$} & 17 & & & & & \\
\hline & & 0 & 0 & 0.001 & 0 & 0.002 \\
\hline \multirow[t]{2}{*}{ QUADAS score <10 } & & 90.6 & 98.7 & 36.008 & 0.119 & 370.78 \\
\hline & 3 & & & & & \\
\hline$P$ & & 0.103 & 0.503 & 0.996 & 0.076 & 0.687 \\
\hline \multirow[t]{2}{*}{ With on-site cytology. } & & 91.5 & 96.5 & 12.136 & 0.120 & 108.83 \\
\hline & 7 & & & & & \\
\hline$P$ & & 0.024 & 0 & 0 & 0.002 & 0 \\
\hline \multirow[t]{2}{*}{ Without on-site cytology. } & & 904 & 96.5 & 14.365 & 0.114 & 170.05 \\
\hline & 13 & & & & & \\
\hline$P$ & & 0 & 0.097 & 0.757 & 0 & 0.263 \\
\hline
\end{tabular}

existing literature and assess the overall performance of EUS-FNA in the diagnosis of solid pancreatic lesions. We found that the pooled sensitivity and specificity were as high as $90.8 \%$ and $96.5 \%$, respectively. The SROC analysis revealed that the $\mathrm{Q}^{*}$ value, which represents the maximum joint sensitivity and specificity, was $91 \%$. These findings suggest that EUS-FNA has a high accuracy in diagnosing solid pancreatic lesions.

The wide variation of the reported sensitivity and specificity of EUS-FNA may be due to a combination of several factors. Operator experience has been proposed as one of the most significant factors that affect the accuracy of EUS-FNA [7, 26, 29], which is a demonstrated significant predictor of diagnostic accuracy in pancreatic lesions in the multivariable model [30]. Since the majority of previous studies depended on the results of one center and the operators had greatly varied experience, the diagnostic performance of EUS-FNA may have been overestimated or underestimated. Thus, an important strength of our meta-analysis is that it included studies performed by operators with different expertise from different centers in different countries. The level of operators' experience should be reported in future studies. In addition, the diagnostic accuracy of EUS-FNA for pancreatic lesions may also be affected by tumor size and location, needle size, and the presence of an on-site cytopathologist [26, 31], although some studies reported that the diagnostic accuracy of EUS-FNA is irrespective of these parameters [26]. Future studies should carefully resolve these problems.

Low NPV has been suggested to be a major drawback of EUS-FNA, and this may limit its clinical utility in patients with suspected pancreatic cancer because early resectable tumors may be missed [21]. An NLR $<0.1$ often suggests that the predictive value of a given diagnostic tool is valid or rather convincing. In the present study, the pooled NLR was 0.118 (95\%CI: 0.086-0.163), which is near 0.1. Considering that we calculated all inadequate biopsies and technical failures in the included studies as FNs, the pooled NLR may have been underestimated. In this regard, the predictive value of EUS-FNA for solid pancreatic lesions is acceptable.

The FN results of EUS-FNA in the diagnosis of pancreatic masses are often caused by a high frequency of inadequate specimens due to several reasons. First, comparative studies of EUS-FNA have demonstrated that larger needles were associated with inferior accuracy rates because of their disadvantage in placement precision in pancreatic lesions located in difficult anatomical positions [32-35]. Second, the number of needle passes through the lesion may affect the collection of adequate 
specimens [35], and a recent report recommended that seven needle passes would be necessary to ensure a highly accurate diagnosis of solid pancreatic lesions by EUS-FNA [36]. Finally, the absence of on-site cytology in the procedure may also reduce the aspiration of adequate sample, although some studies indicated that the unavailability of a cytopathologist did not significantly affect the diagnostic yield [26, 37]. The current study indicated that the absence of on-site cytology has no significant impact on the diagnostic yield (Table 4).

Studies have indicated that EUS-guided FNA biopsy of pancreatic masses is as accurate as CT/US-guided and surgical biopsies [38]. However, EUS-FNA has many advantages over other techniques [39]: (i) the capability to get a sample from a tiny lesion; (ii) the capability to get a sample of the lesion through a part of the intestinal wall and decrease the risk of needle tract seeding; and (iii) the capability to supply extra information about staging of the disease. In particular, EUS-guided FNA can be carried out in the entire pancreas (the hook and tail included) [16, 17], even for difficult or unreachable regions via the percutaneous access or when the percutaneous route is not indicated [12].

Although many diagnostic modalities are currently available for the diagnosis of pancreatic lesions, some are associated with a higher incidence of complications. For example, the rate of complications of CT/US-guided FNA is as high as about $5 \%$, with pancreatitis being the most common complication [39]. In the present study, only $2.2 \%(39 / 1760)$ of cases developed complications, and the majority of complications were mild, self-limited and seldom required transfusion, except that two cases had duodenal perforations that were successfully treated by surgery. These finding suggest that EUS-FNA is a safe technique for the diagnosis of solid pancreatic lesions.

Ultimately in considering to tumor size of pancreatic malignancy was diagnosed by Endoscopic Ultrasound-guided FNA with high accuracy regardless of their tumor size, or location. So we can get initial diagnosis of malignant lesion was obtained by EUS-guided FNA in all adenocarcinoma $\leq$ $10 \mathrm{~mm}$ but unfortunately most of studies included in this study mentioned only the range or median of the tumors size that included sizes $<2 \mathrm{~cm}$ which means that the small size $(<2 \mathrm{~cm})$ can be detected by EUS-FNA even if it cannot be detected by CT or US guided FNA.

\section{Conclusion}

This meta-analysis indicates that EUS-FNA for pancreatic masses has a high overall sensitivity $(91 \%)$ and specificity (96.5\%). Compared with other diagnostic modalities, EUS-FNA may be safer and probably provides advantages over other modalities, such as the ability to detect a tiny lesion and obtain much more diagnostic information.

\section{Acknowledgements}

Not applicable.

\section{Funding}

Not applicable.

Availability of data and materials

All relevant raw data will be freely available to any scientist wishing to use them for non-commercial purposes, without breaching participant confidentiality.

\section{Authors' contributions}

OB - data collection, organization, analysis and writing; FPM-statastics; JZhelp OB collect data; RZ-help OB collect data; LZ- project design,progress guidance and responsible for the whole project. All authors read and approved the final manuscript.

\section{Competing interests}

The authors declare that they have no competing interests.

Consent for publication

Not applicable.

Ethics approval and consent to participate

Not applicable. Since it is a Meta-analysis paper, didn't involve ethics and consent.

\section{Author details}

'Division of Gastroenterology, Union Hospital, Tongji Medical College, Huazhong University of Science and Technology, No. 1277 Jiefang Avenue, Wuhan 430022, Hubei Province, China. ${ }^{2}$ Department of Nuclear Medicine, Union Hospital, Tongji Medical College, Huazhong University of Science and Technology, Hubei Province Key Laboratory of Molecular Imaging, Wuhan 430022, China.

Received: 28 July 2015 Accepted: 11 August 2016

Published online: 31 August 2016

\section{References}

1. Jemal A, Murray T, Ward E, Samuels A, Tiwari RC, Ghafoor A, et al. Cancer statistics, 2005. CA Cancer J Clin. 2005;55(1):10-30.

2. Figures CFa. American Cancer Society. Available at http://www.cancer.org/ acs/groups/content/@nho/documents/document/500809webpdf.pdf. Accessed 5 Feb 2009.

3. Warshaw AL, Fernandez-del CC. Pancreatic carcinoma. N Engl J Med. 1992; 326(7):455-65. doi:10.1056/nejm199202133260706.

4. Erickson RA, Garza AA. Impact of endoscopic ultrasound on the management and outcome of pancreatic carcinoma. Am J Gastroenterol. 2000:95(9):2248-54. doi:10.1111/j.1572-0241.2000.02310.x

5. Podolsky DK, MCPhee MS, Alpert E, Warshaw AL, Isselbacher KJ. Galactosyltransferase isoenzyme II in the detection of pancreatic cancer: comparison with radiologic, endoscopic, and serologic tests. N Engl J Med. 1981;304(22):1313-8. doi:10.1056/nejm198105283042201.

6. Neff CC, Simeone JF, Wittenberg J, Mueller PR, Ferrucci Jr JT. Inflammatory pancreatic masses. Problems in differentiating focal pancreatitis from carcinoma. Radiology. 1984;150(1):35-8. doi:10.1148/radiology.150.1.6689784.

7. Cherian PT, Mohan P, Douiri A, Taniere P, Hejmadi RK, Mahon BS. Role of endoscopic ultrasound-guided fine-needle aspiration in the diagnosis of solid pancreatic and peripancreatic lesions: is onsite cytopathology necessary? HPB. 2010;12(6):389-95. doi:10.1111/j.1477-2574.2010.00180.x.

8. Giovannini M, Seitz JF, Monges G, Perrier H, Rabbia I. Fine-needle aspiration cytology guided by endoscopic ultrasonography: results in 141 patients. Endoscopy. 1995;27(2):171-7. doi:10.1055/s-2007-1005657.

9. Cahn M, Chang K, Nguyen P, Butler J. Impact of endoscopic ultrasound with fine-needle aspiration on the surgical management of pancreatic cancer. Am J Surg. 1996;172(5):470-2. doi:10.1016/s0002-9610(96)00222-X.

10. Bhutani MS, Hawes RH, Baron PL, Sanders-Cliette A, van Velse A, Osborne JF, et al. Endoscopic ultrasound guided fine needle aspiration of malignant pancreatic lesions. Endoscopy. 1997;29(9):854-8. doi:10.1055/s-20071004321. 
11. Faigel DO, Ginsberg GG, Bentz JS, Gupta PK, Smith DB, Kochman ML. Endoscopic ultrasound-guided real-time fine-needle aspiration biopsy of the pancreas in cancer patients with pancreatic lesions. J Clin Oncol. 1997;15(4): 1439-43.

12. Voss M, Hammel P, Molas G, Palazzo L, Dancour A, O'Toole D, et al. Value of endoscopic ultrasound guided fine needle aspiration biopsy in the diagnosis of solid pancreatic masses. Gut. 2000;46(2):244-9.

13. Gress F, Gottlieb K, Sherman S, Lehman G. Endoscopic ultrasonographyguided fine-needle aspiration biopsy of suspected pancreatic cancer. Ann Intern Med. 2001;134(6):459-64.

14. Ylagan LR, Edmundowicz S, Kasal K, Walsh D, Lu DW. Endoscopic ultrasound guided fine-needle aspiration cytology of pancreatic carcinoma: a 3-year experience and review of the literature. Cancer. 2002;96(6):362-9. doi:10. 1002/cncr.10759.

15. Harewood GC, Wiersema MJ. Endosonography-guided fine needle aspiration biopsy in the evaluation of pancreatic masses. Am J Gastroenterol. 2002;97(6):1386-91. doi:10.1111/j.1572-0241.2002.05777.x.

16. Raut CP, Grau AM, Staerkel GA, Kaw M, Tamm EP, Wolff RA, et al. Diagnostic accuracy of endoscopic ultrasound-guided fine-needle aspiration in patients with presumed pancreatic cancer. J Gastrointest Surg. 2003;7(1):118-26. discussion 27-8.

17. Afify AM, al-Khafaji BM, Kim B, Scheiman JM. Endoscopic ultrasound-guided fine needle aspiration of the pancreas. Diagnostic utility and accuracy. Acta Cytol. 2003;47(3):341-8

18. Agarwal B, Abu-Hamda E, Molke KL, Correa AM, Ho L. Endoscopic ultrasound-guided fine needle aspiration and multidetector spiral $C T$ in the diagnosis of pancreatic cancer. Am J Gastroenterol. 2004;99(5):844-50. doi: 10.1111/j.1572-0241.2004.04177.x

19. Ryozawa S, Kitoh H, Gondo T, Urayama N, Yamashita H, Ozawa H, et al. Usefulness of endoscopic ultrasound-guided fine-needle aspiration biopsy for the diagnosis of pancreatic cancer. J Gastroenterol. 2005;40(9):907-11. doi:10.1007/s00535-005-1652-6.

20. Eloubeidi MA, Varadarajulu S, Desai S, Shirley R, Heslin MJ, Mehra M, et al. A prospective evaluation of an algorithm incorporating routine preoperative endoscopic ultrasound-guided fine needle aspiration in suspected pancreatic cancer. J Gastrointest Surg. 2007;11(7):813-9. doi:10.1007/s11605007-0151-x.

21. Krishna NB, Mehra M, Reddy AV, Agarwal B. EUS/EUS-FNA for suspected pancreatic cancer: influence of chronic pancreatitis and clinical presentation with or without obstructive jaundice on performance characteristics. Gastrointest Endosc. 2009;70(1):70-9. doi:10.1016/j.gie.2008.10.030.

22. Touchefeu Y, Le Rhun M, Coron E, Alamdari A, Heymann MF, Mosnier JF, et al. Endoscopic ultrasound-guided fine-needle aspiration for the diagnosis of solid pancreatic masses: the impact on patient-management strategy. Aliment Pharmacol Ther. 2009;30(10):1070-7. doi:10.1111/j.1365-2036.2009. 04138.x

23. Chang KJ, Nguyen P, Erickson RA, Durbin TE, Katz KD. The clinical utility of endoscopic ultrasound-guided fine-needle aspiration in the diagnosis and staging of pancreatic carcinoma. Gastrointest Endosc. 1997;45(5):387-93.

24. Bentz JS, Kochman ML, Faigel DO, Ginsberg GG, Smith DB, Gupta PK. Endoscopic ultrasound-guided real-time fine-needle aspiration: clinicopathologic features of 60 patients. Diagn Cytopathol. 1998;18(2):98-109.

25. Fisher L, Segarajasingam DS, Stewart C, Deboer WB, Yusoff IF. Endoscopic ultrasound guided fine needle aspiration of solid pancreatic lesions: Performance and outcomes. J Gastroenterol Hepatol. 2009;24(1):90-6. doi: 10.1111/j.1440-1746.2008.05569.x.

26. Uehara H, Ikezawa K, Kawada N, Fukutake N, Katayama K, Takakura R, et al. Diagnostic accuracy of endoscopic ultrasound-guided fine needle aspiration for suspected pancreatic malignancy in relation to the size of lesions. J Gastroenterol Hepatol. 2011;26(8):1256-61. doi:10.1111/j.1440-1746.2011.06747.x.

27. Thosani N, Thosani S, Qiao W, Fleming JB, Bhutani MS, Guha S. Role of EUSFNA-based cytology in the diagnosis of mucinous pancreatic cystic lesions: a systematic review and meta-analysis. Dig Dis Sci. 2010;55(10):2756-66. doi: 10.1007/s10620-010-1361-8.

28. Whiting P, Rutjes AW, Reitsma JB, Bossuyt PM, Kleijnen J. The development of QUADAS: a tool for the quality assessment of studies of diagnostic accuracy included in systematic reviews. BMC Med Res Methodol. 2003;3:25. doi:10.1186/1471-2288-3-25.

29. Wiersema MJ, Vilmann P, Giovannini M, Chang KJ, Wiersema LM. Endosonography-guided fine-needle aspiration biopsy: diagnostic accuracy and complication assessment. Gastroenterology. 1997;112(4):1087-95.
30. Harewood GC, Wiersema LM, Halling AC, Keeney GL, Salamao DR, Wiersema MJ. Influence of EUS training and pathology interpretation on accuracy of EUS-guided fine needle aspiration of pancreatic masses. Gastrointest Endosc. 2002:55(6):669-73.

31. Hwang CY, Lee SS, Song TJ, Moon SH, Lee D, Park Do H, et al. Endoscopic ultrasound guided fine needle aspiration biopsy in diagnosis of pancreatic and peripancreatic lesions: a single center experience in Korea. Gut Liver. 2009;3(2):116-21. doi:10.5009/gnl.2009.3.2.116.

32. Itoi T, Itokawa F, Sofuni A, Nakamura K, Tsuchida A, Yamao K, et al. Puncture of solid pancreatic tumors guided by endoscopic ultrasonography: a pilot study series comparing Trucut and 19-gauge and 22-gauge aspiration needles. Endoscopy. 2005;37(4):362-6. doi:10.1055/s-2004-826156.

33. Levy MJ, Jondal ML, Clain J, Wiersema MJ. Preliminary experience with an EUS-guided trucut biopsy needle compared with EUS-guided FNA. Gastrointest Endosc. 2003:57(1):101-6. doi:10.1067/mge.2003.49.

34. Larghi A, Verna EC, Stavropoulos SN, Rotterdam H, Lightdale CJ, Stevens PD. EUS-guided trucut needle biopsies in patients with solid pancreatic masses: a prospective study. Gastrointest Endosc. 2004;59(2):185-90.

35. Varadarajulu S, Fraig M, Schmulewitz N, Roberts S, Wildi S, Hawes RH, et al. Comparison of EUS-guided 19-gauge Trucut needle biopsy with EUSguided fine-needle aspiration. Endoscopy. 2004;36(5):397-401. doi:10.1055/s2004-814316.

36. LeBlanc JK, Ciaccia D, Al-Assi MT, McGrath K, Imperiale T, Tao LC, et al. Optimal number of EUS-guided fine needle passes needed to obtain a correct diagnosis. Gastrointest Endosc. 2004;59(4):475-81.

37. Hikichi T, Irisawa A, Bhutani MS, Takagi T, Shibukawa G, Yamamoto G, et al. Endoscopic ultrasound-guided fine-needle aspiration of solid pancreatic masses with rapid on-site cytological evaluation by endosonographers without attendance of cytopathologists. J Gastroenterol. 2009;44(4):322-8. doi:10.1007/s00535-009-0001-6.

38. Mallery JS, Centeno BA, Hahn PF, Chang Y, Warshaw AL, Brugge WR. Pancreatic tissue sampling guided by EUS, CT/US, and surgery: a comparison of sensitivity and specificity. Gastrointest Endosc. 2002:56(2): 218-24.

39. Iwashita T, Yasuda I, Doi S, Nakashima M, Tsurumi H, Hirose Y, et al. Endoscopic ultrasound-guided fine-needle aspiration in patients with lymphadenopathy suspected of recurrent malignancy after curative treatment. J Gastroenterol. 2009;44(3):190-6. doi:10.1007/s00535-008-2302-6.

\section{Submit your next manuscript to BioMed Central and we will help you at every step:}

- We accept pre-submission inquiries

- Our selector tool helps you to find the most relevant journal

- We provide round the clock customer support

- Convenient online submission

- Thorough peer review

- Inclusion in PubMed and all major indexing services

- Maximum visibility for your research

Submit your manuscript at www.biomedcentral.com/submit
) Biomed Central 